\title{
Panorama do saneamento básico em cidades consorciadas do interior da Paraíba
}

Submissão: 26/05/2021

Aceite: $20 / 07 / 2021$

\author{
Sharliany Fernandes Vieira ${ }^{1}$ \\ Emanuely dos Santos Marques ${ }^{2}$ \\ Francisco do O. de Lima Júnior ${ }^{3}$ \\ Josué Alencar Bezerra ${ }^{4}$
}

\begin{abstract}
Resumo
O saneamento básico é um elemento essencial para o desenvolvimento sociopolítico e econômico, todavia a prestação desse serviço é um desafio para os municípios. Ações conjuntas e articuladas por Consórcios Intermunicipais possibilitam aos consorciados melhorias no desempenho e otimização de recursos para a disponibilização de determinados serviços públicos. O presente trabalho tem por objetivo apresentar um panorama acerca da situação do saneamento básico dos doze municípios do sertão paraibano que integram o Consórcio Público Intermunicipal de Desenvolvimento Sustentável e Inovação do Estado da Paraíba - CONDESPB. A pesquisa é classificada como descritiva, pois buscou caracterizar os municípios com base nos indicadores que conduzem ao entendimento da estrutura do saneamento básico. $O$ estudo foi realizado com base em dados secundários coletados principalmente nos sites do IBGE e no Atlas do Desenvolvimento Humano do Brasil. Também foi realizado levantamento documental para conhecimento dos aspectos básicos da constituição do CONDESPB e sua possível atuação e influência na área pesquisada. Os resultados apontam que entre os municípios consorciados existem congruências e divergências em se tratando de saneamento básico e que a participação em um consórcio amplia as possibilidades de ações conjuntas para a atuação em territórios a fim de resolver problemas comuns, porém os municípios do CONDESPB, apesar de diversas tentativas, usufruíram pouco e/ou não tiverem maturidade para se apropriarem desses benefícios. Conclui-se que o consórcio intermunicipal tem o potencial de contribuir para o desenvolvimento da região, implementando uma gestão colaborativa por meio de estratégias e políticas que privilegiem a universalização dos serviços de saneamento básico de boa qualidade.
\end{abstract}

Palavras chaves: Saneamento básico; Consórcios Intermunicipais; Municípios de pequeno porte.

\section{Overview of basic sanitation in consortium of cities in the countryside of Paraíba}

\begin{abstract}
Basic sanitation is an essential element for socio-political and economic development however the provision of this service is a challenge for municipalities. Joint and articulated actions by Intermunicipal Consortiums allow consortium members to improve their performance and optimize resources for the provision of certain public services. The present work aims to present an overview of the situation of basic sanitation in the twelve municipalities in the interior of Paraiba that are part of the Intermunicipal Public Consortium for Sustainable Development and Innovation of the State of Paraiba - CONDESPB. The research is classified as descriptive, as it sought to characterize the municipalities based on the indicators that lead to the understanding of the basic sanitation structure. The study was conducted based on secondary data collected mainly on the websites of the IBGE and the Human Development Atlas of Brazil. A documentary survey was also carried out to understand the basic aspects of the constitution of CONDESPB and its possible role and influence in the researched area. The results show that among the consortium municipalities there are congruences and divergences when it comes to basic sanitation and that the participation in a consortium expands the possibilities of joint actions to act in territories in order to solve common problems, however the municipalities of CONDESPB did not enjoy much and / or are not mature enough to take advantage of these benefits. It is concluded that the intermunicipal consortium has the potential to contribute to the development of the region,
\end{abstract}

\footnotetext{
${ }^{1}$ Mestranda no Programa de Pós-Graduação em Planejamento e Dinâmicas Territoriais no Semiárido (PLANDITES) da Universidade Estadual do Rio Grande do Norte (UERN). E-mail: sharliany@hotmail.com

${ }^{2}$ Mestranda no Programa de Pós-Graduação em Planejamento e Dinâmicas Territoriais no Semiárido (PLANDITES) da Universidade Estadual do Rio Grande do Norte (UERN). E-mail: emanuely.marques@hotmail.com

3 Doutorado em Desenvolvimento Econômico (IE-UNICAMP). Professor do Programa de Pós-Graduação em Planejamento e Dinâmicas Territoriais do Semiárido da UERN. E-mail: lima.junior@urca.br

${ }^{4}$ Doutorado em Geografia (UECE). Professor do Programa de Pós-Graduação em Planejamento e Dinâmicas Territoriais do Semiárido da Universidade Estadual do Rio Grande do Norte-UERN. E-mail: josueabezerra@gmail.com
} 
implementing collaborative management through strategies and policies that favor the universalization of good quality basic sanitation services.

Key words: Basic sanitation; Intermunicipal Consortia; Small municipalities.

\section{Introdução}

A preocupação com as questões relativas ao saneamento básico no Brasil remonta um percurso histórico institucionalizado em virtude da necessidade de assistir o território com políticas públicas que atendam à demanda dos problemas sociais, de saúde e econômicos que se fazem presentes nas cidades. O conjunto das transformações ocorridas no espaço urbano refletem as manifestações sociais, cheias de símbolos e campos de lutas, que se desenlaçam de forma articulada e fragmentada em função das ações concretas dos atores sociais, da dinâmica de acumulação de capital, das necessidades mutáveis das relações de produção, e dos conflitos de classe, que ao longo do tempo definem a forma como o espaço é produzido e consumido (CORRÊA, 2004).

Do ponto de vista normativo o saneamento básico no Brasil ganhou contornos desde a Carta Magna correspondente à Constituição de 1988, que norteia o desenvolvimento de políticas públicas de saneamento no Brasil. No entanto, a forma como estas políticas devem ser desenvolvidas passa pelo campo infraconstitucional, inserindo nessa modalidade a Lei Federal 11.445/2007, o Plano Nacional de Saneamento Básico (PLANSAB) de 2013, e as Diretrizes para a Definição da Política e Elaboração de Planos Municipais e Regionais de Saneamento Básico de 2010 que defendem a universalização do acesso aos serviços de saneamento básico como o principal objetivo para a promoção das políticas públicas no setor (SOUSA, SOUSA, ALVARES, 2015)

De acordo com a Constituição de 1988, em seu Artigo 21, compete à União instituir diretrizes para o desenvolvimento urbano, inclusive habitação, saneamento básico e transportes urbanos. Ainda sobre a Carta Magna observa-se a tendência à descentralização das políticas de saneamento básico quando estabelece que a promoção de programas de construção de moradias e a melhoria das condições habitacionais e de saneamento básico são competências comuns à União, Estados, Distrito Federal e dos Municípios (BRASIL, 1988).

No âmbito da política urbana, o Estatuto da Cidade constitui a Lei Federal de n.으 10.257/2001 que representou um avanço constitucional com o propósito de trazer melhorias para o planejamento urbano no Brasil, bem como cumpriu o papel de aproximar a gestão municipal ao cidadão. A sua criação tangencia a regulamentação dos artigos 182 e 183 da 
Constituição Federal que tratam da política de desenvolvimento urbano e da função social da propriedade. A referida lei representa uma consolidação de conquistas reivindicatórias de mais de três décadas pelos vários setores da sociedade, especialmente os movimentos sociais (DIAS, NEPOMUCENO, 2017).

De acordo com o Estatuto das Cidades, é competência da União instituir diretrizes para o desenvolvimento urbano, inclusive habitação, saneamento básico e transportes urbanos, dentre outras atribuições. No que diz respeito à promoção de programas de construção de moradias e à melhoria das condições habitacionais e de saneamento básico expressa que é de competência em conjunto da União, Estados, Distrito Federal e Municípios (BRASIL, 2011). Nesse contexto são criadas as diretrizes para a definição da política e elaboração de planos municipais e regionais de saneamento básico que devem servir de apoio e orientação para a elaboração das políticas e planos que tratem do saneamento básico, com vista a garantir o princípio da universalização desses serviços que prezem pela qualidade e controle social (BRASIL, 2010).

De acordo com essas diretrizes cabe à administração pública municipal a titularidade dos serviços de saneamento básico, incumbindo-lhe o desafio de formular a política pública para o seu domínio e elaborar o plano de saneamento básico. Além disso a Lei 11.107/05 - Lei de Consórcios Públicos prever a elaboração de Plano Regional de Saneamento Básico no âmbito da gestão associada mediante consórcio público ou prestação regionalizada. Ressalte-se que a Lei dos Consórcios Públicos ampliou as possibilidades de prestação dos serviços e passou a incentivar os municípios a criarem consórcios em áreas com interesses comuns para aprimorar o planejamento e a prestação dos serviços (BRASIL, 2010, BRASIL, 2009).

A constituição de consórcios intermunicipais para resolução de problemas relativos ao saneamento básico no Brasil é uma alternativa exitosa. Como exemplo é possível destacar o Consorcio Intermunicipal de Saneamento Ambiental do Paraná - CISMAE. Segundo Piterman (2016), o CISMAE foi constituído face ao novo cenário estabelecido pela Lei no 11.107/2005, Lei dos Consórcios Públicos, e pela Lei no 11.445/2007, Lei de Diretrizes de Saneamento Básico. Os resultados do estudo da autora revelaram que a criação do consórcio público é um importante fator para estimular a implantação e gestão das políticas públicas de saneamento adstritas em seu território e que os benefícios, em razão da existência do consórcio para os municípios, são múltiplos. Entre estes, ela cita a potencialização de recursos socioeconômicos, tecnológicos e humanos e, decorrente deles, têm-se a racionalização de aplicação de recursos, maior transparência na sua aplicação, maior segurança jurídica ao acordo de cooperação consorcial e o empoderamento político. 
Os dados disponíveis no Observatório Municipalista de Consórcios Públicos (2021) indicam que $1 / 3$ dos municípios paraibanos participam de ao menos um Consórcio Público, e que prepondera a existência de consórcios com atuação na área da saúde, com 72 municípios consorciado. Com relação ao saneamento básico foi verificado que existem 17 municípios integrantes de consórcios para solucionar problemas relativos à destinação adequada dos resíduos sólidos, cujo objetivo de associação se resume à condução dos municípios à adequação à Política Nacional de Resíduos Sólidos instituída pela Lei № 12.305/10 de 2010 (OMCP, 2021).

Diante de tais delineamentos o presente trabalho tem como premissa responder o seguinte questionamento: Qual é a situação do saneamento básico em cidades consorciadas do interior da Paraíba? A pesquisa tem como objetivo geral traçar o panorama do saneamento básico dos 12 (doze) municípios integrantes do Consórcio Público Intermunicipal de Desenvolvimento Sustentável e Inovação do Estado da Paraíba - CONDESPB.

A entidade tem aproximadamente uma década de existência e foi fundada com o intuito de conseguir recursos junto ao Governo Federal para a construção de um aterro sanitário que pudesse conduzir os municípios associados à destinação correta dos resíduos e, dessa forma, se adequarem à Política Nacional de Resíduos Sólidos. Ao longo dos anos, a área de atuação do CONDESPB foi sendo ampliada, todavia a preocupação com as questões ambientais se manteve na pauta dos principais assuntos de interesse comum entre os gestores.

O artigo foi estruturado com base nos seguintes tópicos: Introdução, que compreende a contextualização do problema de pesquisa e sua problematização; o Referencial Teórico, com os fundamentos que permitem situar o problema de pesquisa num contexto histórico institucionalizado, verificar os avanços ou caminhos percorridos para implementação do saneamento básico nas pequenas cidades com uma perspectiva para o desenvolvimento de ações consorciadas; apresenta também os Procedimentos Metodológicos utilizados, trazendo uma caracterização do CONDESPB; os Resultados, que apresentam as ações da CONDESPB no quesito saneamento básico com suas limitações e potencialidades; e, por fim, são apresentadas as Considerações Finais com proposições que justificam a viabilidade dos consórcios para melhorar a atuação dos municípios. 


\section{Referencial teórico}

\subsection{A institucionalização do saneamento básico no Brasil}

A natureza das decisões políticas no Brasil percorreu uma trajetória que foi influenciada pela atuação do Estado que se deu ora em maior, ora em menor grau. É preciso considerar que as ações do Estado se dão nos três níveis: federal, estadual e municipal. Na primeira metade do século XX, a abordagem teórica das políticas foi caracterizada por um viés institucionalista que defendia a ideia normativa das instituições políticas formais, como as Constituições e as Leis que constrangiam o comportamento dos indivíduos pelo fato desse viés centrar-se em análises de cunho especulativo, descritivo e formalista, negligenciando os fatos objetivos da política. $\mathrm{Na}$ década de 1990 esse modelo institucionalista foi criticado em decorrência da centralidade do Estado, sendo incorporado um modelo que prezasse pelo equilíbrio do papel do Estado com a sociedade e onde a perspectiva mais centrada na própria política teria mais vigor (CORRÊA, 2004; SOUSA, COSTA, 2016).

O contexto da institucionalização do saneamento básico no Brasil inicia-se com políticas voltadas ao campo da saúde, pois na primeira década do século XX o país passava pelas constantes epidemias de febre amarela e outras doenças que exigiam uma intervenção federal nos assuntos de saúde pública, e que, posteriormente, passou para uma ampliação de intervenção política que conduziu à reforma sanitária (SOUSA, COSTA, 2016).

A expansão da industrialização que teve seu ponta pé na década de 1930, intensificando nos anos de 1950 e 1960, provocou um aumento na densidade populacional urbana acentuando uma forte precarização dos serviços de infraestrutura e abastecimento de água. Este cenário demandou uma articulação dos três entes federados, desenhando novas formas de intervenção com o desenvolvimento de múltiplos arranjos de alcance regional e local. Movido por este cenário de caos urbano, o saneamento básico passou a fazer parte da agenda pública, relegando as ações de saneamento ao setor de obras e habitação. Este processo culminou, em 1971, com a criação do Pacto Nacional de Saneamento - PLANASA, que correspondeu a principal política pública para o saneamento básico (SOUSA, COSTA, 2016).

A criação do PLANASA consolidou o princípio de autossustentação do setor de saneamento básico e o conceito industrial que prioriza o problema da água e dos esgotos sanitários, com investimentos em melhorias na saúde e na qualidade de vida, possibilitadas por meio da adoção de práticas gerenciais modernas. Ressalte-se que a política do PLANASA favoreceu o fortalecimento dos operadores públicos estaduais e adoção de ações mais 
centralizadas. O PLANASA representou um marco no crescimento dos índices de abastecimento de água e de coleta de esgoto. Essa normativa foi abruptamente desmontada devido a sucessivas crises econômicas que levaram à constante elevação das tarifas e implicou na autossustentação a qualquer custo (FARIA R., FARIA S., 2004; BASTOS, 2009).

Observou-se, em uma perspectiva histórica, um vazio institucional para o saneamento básico devido à instabilidade das ações federais evidenciada por mudanças frequentes da pasta governamental do setor de saneamento e a falta de definição das competências e responsabilidades dentro do Governo Federal. Vale destacar a inexistência de orientações internas sobre diretrizes, requisitos e procedimentos mínimos necessários para a orientação dos programas de governo. Motivada por essa lacuna foi criada a Lei Nacional de Saneamento Básico de no 11.445/2007, que tem como função disciplinar a Política Nacional de Saneamento Básico, introduzindo um marco regulatório efetivo para o estabelecimento das diretrizes nacionais para o saneamento e as políticas federais do saneamento (BRASIL, 2009).

Os princípios que regem esta lei atribuem ao saneamento básico uma importância notória para a qualidade de vida em todos os âmbitos, seja social, de saúde, por meio de serviços da infraestrutura, de proteção ambiental. Nesse sentido esta lei apregoa a universalização do acesso ao saneamento básico, proporcionada conforme as necessidades e maximização da eficácia das ações e resultados que prezem pela segurança, qualidade e regularidade orientadas para o desenvolvimento social e econômico (BRASIL, 2007).

Mesmo diante da melhoria proporcionada pela lei de no $11.445 / 2007$ a efetividade das ações de saneamento básico não era satisfatória em virtude da complexidade do problema, posto que os arranjos institucionais e medidas técnicas não supriam a demanda por serviços nesse setor. Diante disso foi elaborado o Plano Nacional de Saneamento Básico - PLANSAB, que representou um instrumento que viabilizaria as diretrizes e políticas propagadas na Lei Nacional do Saneamento Básico. O PLANSAB corresponde a um conjunto de medidas pormenorizadas que trazem robustez para as políticas regionais, estaduais e municipais, incluindo a fixação de metas de cobertura e qualidade dos serviços e mecanismos de controle, monitoramento e avaliação sistemática das ações, além de servir de orientação aos planos regionais, estaduais e municipais (BRASIL, 2009).

Os parâmetros e diretrizes estabelecidos na Lei no 11.445/2007 trazem as precondições basilares para o saneamento básico que elege o planejamento, a regulação, a fiscalização e o controle social como funções essenciais da gestão para viabilizar a prestação dos serviços e execução das ações de saneamento. Observadas essas orientações avaliaram-se numa 
perspectiva histórica que as políticas de saneamento precisariam de uma reorganização da política federal, uma ampliação e ajustes técnicos para melhor adequação à realidade dos municípios. Soma-se a isto a necessidade de a União assumir as suas responsabilidades, especialmente no que se refere à regulação dos serviços e ao financiamento de saneamento (BRASIL, 2011).

Recentemente a política de saneamento básico passou por um processo de modernização com a aprovação pelo senado da nova lei do saneamento básico, a LEI 14.026/2020 que tem como objetivo universalizar e qualificar a prestação dos serviços no setor. O que motivou a criação dessa lei são os problemas gerados em decorrência das situações de calamidade pública e de saúde agravados pela precariedade desses serviços, soma-se a isto o contexto de urgência provocados pela pandemia do Coronavírus. Entende-se que os serviços de saneamento básico têm um efeito multiplicador para a geração de empregos, saúde, educação e melhoria da qualidade de vida das pessoas (SENADO..., 2020; NOVO..., 2020).

2.2 A gestão de saneamento básico nas pequenas cidades e a participação dos Consórcios Intermunicipais

De início é preciso ter uma compreensão do que vem a ser o termo 'pequenas cidades'. Em um entendimento da hierarquia urbana, as cidades são distinguidas por uma escala de tamanho: cidade grande, média e pequena. Do ponto de vista da geografia, o termo "cidade pequena" é muito utilizado por instituições estatísticas que consideram o número de habitantes como fator determinante para esta nomenclatura. Neste sentido, o critério demográfico recebe especial importância para medir o tamanho da cidade. Diante desse entendimento cidades pequenas são aquelas que possuem uma população de até 20.000 habitantes. De forma análoga a este critério, Calvo et al. (2016), caracteriza os municípios de pequeno porte como aqueles que possuem uma população com até 25.000 habitantes. Municípios com 25 a 100 mil habitantes são de médio porte, e municípios com mais de 100 mil habitantes são considerados de grande porte (FRESCA, 2001; MAIA, 2010).

No entanto os autores colocam que esta análise do tamanho do município pelo critério demográfico é bastante restrita, pois não reflete uma realidade plural, que é o caso das cidades brasileiras que possuem expressivas diferenças regionais, sendo necessário inserir o contexto socioeconômico que caracterize um eixo norteador a fim de igualar as cidades com populações similares e com essências distintas entre si (FRESCA, 2001; MAIA, 2010). 
Ciente das disparidades existentes entre as regiões do Brasil, o termo 'pequena cidade' não pode ser limitado ao tamanho da população, pois outras peculiares serão percebidas de acordo com a localização e os fatores socioculturais inerentes ao contexto. A exemplo disso, os estudos de Maia (2010) alertam que as pequenas cidades do Nordeste têm particularidades econômicas pontuais, em especial a forte relação campo-cidade que se revela na economia municipal, a agricultura e a pecuária aparecem como os principais componentes econômicos, assim como a incipiente oferta de serviços e ainda um comércio bastante restrito. Pequenas cidades de outras regiões do país certamente apresentam caracterizas distintas.

De acordo com a Lei Nacional de Saneamento Básico de no 11.445/2007 a gestão do saneamento básico compreende o conjunto de serviços, infraestrutura e instalações operacionais relacionadas ao abastecimento de água potável, esgotamento sanitário, limpeza urbana e manejo de resíduos sólidos, drenagem e manejo das águas pluviais (BRASIL, 2007).

A gestão do saneamento básico no Brasil se caracteriza por uma abordagem tecnocêntrica baseada numa visão da engenharia sanitária diferente da visão sistêmica que busca alinhar a técnica com um viés político (BRITTO, 2012). No que se refere à política de abastecimento urbano de água e esgoto estabelecidas pelo PLANASA, o modelo de gestão tinha uma estrutura centralizada. No entanto, no período de 1990 a 1994 houve a extinção do PLANASA, trazendo reformas administrativas e econômicas realizadas no campo institucional, mas sem produção de resultados significativos na melhoria do sistema de gestão (FARIA, FARIA, 2004).

O modelo de centralização das decisões e princípios burocráticos implantado pelo PLANASA perdurou muitos anos na condução das políticas de saneamentos básico. Por aproximadamente quatro décadas, os municípios delegavam suas decisões de gestão de saneamento básico às Companhias Estaduais - CEBs. Mas com o advento da Lei 11.445/2007 incorreu aos municípios uma série de desafios que lhes induziram a se posicionar mais efetivamente sobre este setor. Nesse sentido, os municípios incumbidos de desenvolver gestão de saneamento básico, seja através de gestão direta, seja por delegação à empresa estadual, seja pela delegação à empresa privada a fim de que se consolide o novo papel atribuído aos municípios (BRITTO, 2012).

No âmbito dos municípios, a gestão de saneamento básico consiste no conjunto de ações técnicas e administrativas destinadas a proporcionar os serviços essenciais do saneamento. Para isso, deve colocar à disposição da população adequados serviços de abastecimento de água e esgotamento sanitário, de manejo de águas pluviais e de manejo de resíduos sólidos, mantendo- 
os em bom estado de conservação e funcionamento, bem como prever e garantir as demandas futuras. Com isso surge a necessidade de definir um modelo de gestão e de sua organização administrativa; constituir, formar e capacitar a equipe técnica; elaborar projetos e planos de trabalho, bem como estabelecer mecanismos de financiamento (CONFEDERAÇÃO NACIONAL DOS MUNICÍPIOS, 2009).

Os desafios para a gestão do saneamento básico nos municípios de pequeno porte são discutidos por Lisboa, Heller e Silveira (2013), tendo em vista a necessidade de implementação do Plano Municipal de Saneamento Básico. De acordo com os autores, as principais dificuldades para elaboração do plano de saneamento são a indisponibilidade de recursos financeiros, a limitação quanto à qualificação profissional e capacidade técnica municipal, a falta de integração dos órgãos que compõe o saneamento, bem como a falta de vontade política.

Os pequenos municípios convivem ainda com a dificuldade de ter acesso aos recursos financeiros como resultado da incapacidade técnica para elaborar projetos que se enquadrem nas regras de acesso aos recursos e que viabilizem a solicitação de financiamento. No contexto dos pequenos municípios, as políticas têm priorizado medidas estruturais em detrimento da ampliação das medidas estruturantes, necessárias para proporcionar uma maior sustentabilidade às ações implantadas (BORJA, 2014). Diante desses desafios e seguindo o que preconiza a Lei $11.455 / 2007$, os municípios precisam por meio de uma gestão participativa criar estratégias com políticas que privilegiem a universalização dos serviços de saneamento básico de boa qualidade que envolvem a compreensão das demandas habitacionais e o planejamento do solo urbano (ROSSONI et al., 2019).

A gestão do saneamento básico evoluiu no sentido de que foram construídos novos arranjos e estratégias para atuação nessa área, por exemplo a cooperação entre os entes federados. Nessa perspectiva dá-se voz aos consórcios públicos, que se constituem num instrumento de gestão que, através da cooperação federativa, possibilita articulação institucional pautada em pactuação que assegura a intergovernabilidade e preserva a autonomia e a competência de cada esfera de governo (CONFEDERAÇÃO NACIONAL DOS MUNICÍPIOS, 2009).

Os consórcios intermunicipais são uma alternativa eficaz de cooperação, especialmente para os pequenos municípios que possuem objetivos comuns e características semelhantes constituindo uma determinada região. Por meio dos consórcios os municípios podem desempenharem melhor as suas funções de planejamento, gestão e fomento, permitindo aos municípios alcançarem patamares superiores de gestão do que poderia ser obtido com ações executadas individualmente (FERNANDES, 2017; SOUSA, GUEDES, 2019). 
Com base no OMCP (2020), existem 487 Consórcios Públicos no Brasil, dos quais cerca de 75\% estão localizados nas regiões Sudeste e Sul. A região Nordeste ocupa a terceira posição com $13 \%$, seguida da região Centro-oeste com $10 \%$ e da região Norte com apenas $2 \%$ do total. Afunilando a pesquisa, verificou-se que no Estado da Paraíba 89 municípios são integrantes de um Consórcio Público Intermunicipal, ou seja, 45,3\% dos municípios paraibanos participam de consórcios intermunicipais. Nesse contexto, apresenta-se o consórcio pesquisado neste trabalho.

A referida entidade foi fundada em 13 de junho de 2011 sob a forma de associação pública, sem fins lucrativos, de personalidade jurídica de direito público, e foi nomeada como Consórcio Intermunicipal de Desenvolvimento Regional da Nascente do Rio do Peixe. Sua formação inicial foi composta por 04 (quatro) municípios: Bernardino Batista, Joca Claudino, Poço Dantas e Poço de José de Moura. Cinco anos mais tarde o Consórcio recebeu a adesão do município de Uiraúna.

No ano de 2019 a associação foi reestruturada e passou a ser chamada Consórcio Público Intermunicipal de Desenvolvimento Sustentável e Inovação do Estado da Paraíba (CONDESPB). A associação é formada atualmente por 12 (doze) municípios do sertão paraibano: Bernardino Batista, Joca Claudino, Poço Dantas, Poço de José de Moura, Santa Helena, São José da Lagoa Tapada, São José de Piranhas, São João do Rio do Peixe, Sousa, Triunfo, Uiraúna, Vieirópolis.

Em suma, até 2016 o Consórcio era composto por 5 (cinco) municípios cujo somatório da população era de aproximadamente 30.000 habitantes distribuídos numa área de $617,36 \mathrm{Km}^{2}$ (somatório da área total dos municípios integrantes). Em 2019, após a reestruturação da associação que resultou na inserção de 7 (sete) novos municípios (mencionados anteriormente) o Consórcio passou a abranger uma população de mais de 160.000 pessoas o que representa um aumento de 433 \% de cidadãos atendidos. Em se tratando de extensão territorial, a área de abrangência da associação que era de pouco mais de $600 \mathrm{~km}^{2}$ passou a quase $4.000 \mathrm{~km}^{2}$.

No estatuto do CONDESPB descreve as possíveis áreas de atuação por meio da instituição: A constituição do Consórcio Intermunicipal tem também por finalidade a adoção de
políticas públicas na área de Aquisição e/ou uso de máquinas e equipamentos;
Assistência Social; Capacitação Administrativa; Compartilhamento de equipamentos de
pessoal técnico; Compras Conjuntas (de uma licitação para atender os municípios
consorciados) Desenvolvimento agropecuário; Desenvolvimento Cultural e Turismo;
Desenvolvimento econômico; Educação; Elaboração de Planos Diretores e de
Desenvolvimento Regional; Esporte e Lazer; Gerenciamento Integrado de Resíduos
Sólidos (Coleta de Resíduos Sólidos Urbanos, Coleta de Resíduos Sólidos especiais,
Coleta seletiva, Limpeza Urbana, Disposição final do lixo); Habitação; Implantação de
Agroindústrias; Meio ambiente, recursos hídricos e saneamento; obras públicas;
processamento de dados; Qualificação da mão de obra; Transportes e unidades de
saúde consorciais (hospitais, centros clínicos, laboratórios, farmácias de manipulação),
conforme definido no protocolo de intenções constante do Anexo único, parte
integrante desta Lei (BRASIL, 2011). 
O CONDESPB foi criado com foco principal de atuação na área de resíduos sólidos e projetos hídricos. Todavia, segundo o seu Estatuto Social, a associação pode atuar em diversas áreas, dentre as quais é possível destacar o interesse por aspectos relacionados ao saneamento.

\section{Percurso metodológico}

A presente pesquisa é respaldada em ensaio bibliográfico construído a partir da literatura relacionada ao saneamento básico, bem como nos principais marcos legislativos que regulamentaram a gestão e a política do saneamento básico no Brasil. Também foram introduzidos alguns comentários acerca da relação dos Consórcios Públicos Intermunicipais com o saneamento básico dos munícipios.

Feita esta abordagem teórica, foi realizado um estudo descritivo que compara as características dos municípios que congregam o Consórcio Público Intermunicipal de Desenvolvimento Sustentável e Inovação do Estado da Paraíba - CONDESPB, que se trata da primeira associação de municípios por meio de Consórcio Público no sertão paraibano.

Quanto à abordagem, a pesquisa é quali-quantitava, pois exigiu a coleta de dados estatísticos e informações gerais referentes à caracterização dos municípios da área de atuação do CONDESPB. Foram coletados dados referentes à situação do saneamento básico dos municípios integrantes da pesquisa com utilização de indicadores.

No que tange à base de dados, o estudo foi constituído a partir de dados secundários obtidos nos sites do IBGE, por exemplo Censo Demográfico, IBGE Cidades, Plano Nacional de Desenvolvimento Humano. E, também, se recorreu ao Atlas do Desenvolvimento Humano do Brasil. Foi realizado levantamento documental para obtenção de informações a respeito da constituição do referido Consórcio, por exemplo Leis, Atas e o Estatuto que estão disponíveis no site da instituição. A tabela 1 abaixo apresenta características dos 12 (doze) municípios do sertão paraibano que integram o CONDESPB. 
Tabela 1 - População/área/densidade demográfica dos municípios integrantes do CONDESPB

\begin{tabular}{lcccc}
\hline MUNICíPIO & $\begin{array}{c}\text { POPULAÇÃO } \\
\text { (CENSO 2000) }\end{array}$ & $\begin{array}{c}\text { POPULAÇÃo } \\
\text { (CENSO 2010) }\end{array}$ & $\begin{array}{c}\text { ÁREA TOTAL } \\
\text { Km }\end{array}$ & $\begin{array}{c}\text { DENSIDADE } \\
\text { DEMOGRÁFICA } \\
\text { HAB./Km2 }\end{array}$ \\
\hline Bernardino Batista & 2.559 & 3.075 & 50,6 & 60,74 \\
Joca Claudino & 2.568 & 2.615 & 74,0 & 35,33 \\
Poço Dantas & 3.828 & 3.751 & 97,2 & 38,57 \\
Poço de José de Moura & 3.529 & 3.978 & 101,0 & 39,40 \\
Santa Helena & 6.170 & 5.369 & 210,3 & 25,53 \\
São José da Lagoa Tapada & 7.184 & 7.564 & 341,8 & 22,13 \\
São José de Piranhas & 17.876 & 19.096 & 677,3 & 28,19 \\
São João do Rio do Peixe & 17.661 & 18.201 & 474,4 & 38,36 \\
Sousa & 62.635 & 65.803 & 738,5 & 89,10 \\
Triunfo & 9.053 & 9.220 & 219,9 & 41,93 \\
Uiraúna & 13.681 & 14.584 & 294,5 & 49,52 \\
Vieirópolis & 4.672 & 5.045 & 146,8 & 34,37 \\
\hline
\end{tabular}

Fonte: Censos Demográficos de 2000 e de 2010 IBGE (2020)

Faz-se necessário apresentar a localização geográfica dos municípios que compõem a associação. De acordo com o IBGE, os municípios do CONDESPB estão distribuídos dentro dos limites das Regiões Intermediárias Sousa-Cajazeiras, conforme demonstrado no mapa 1.

Mapa 1 - Localização Geográfica do CONDESPB

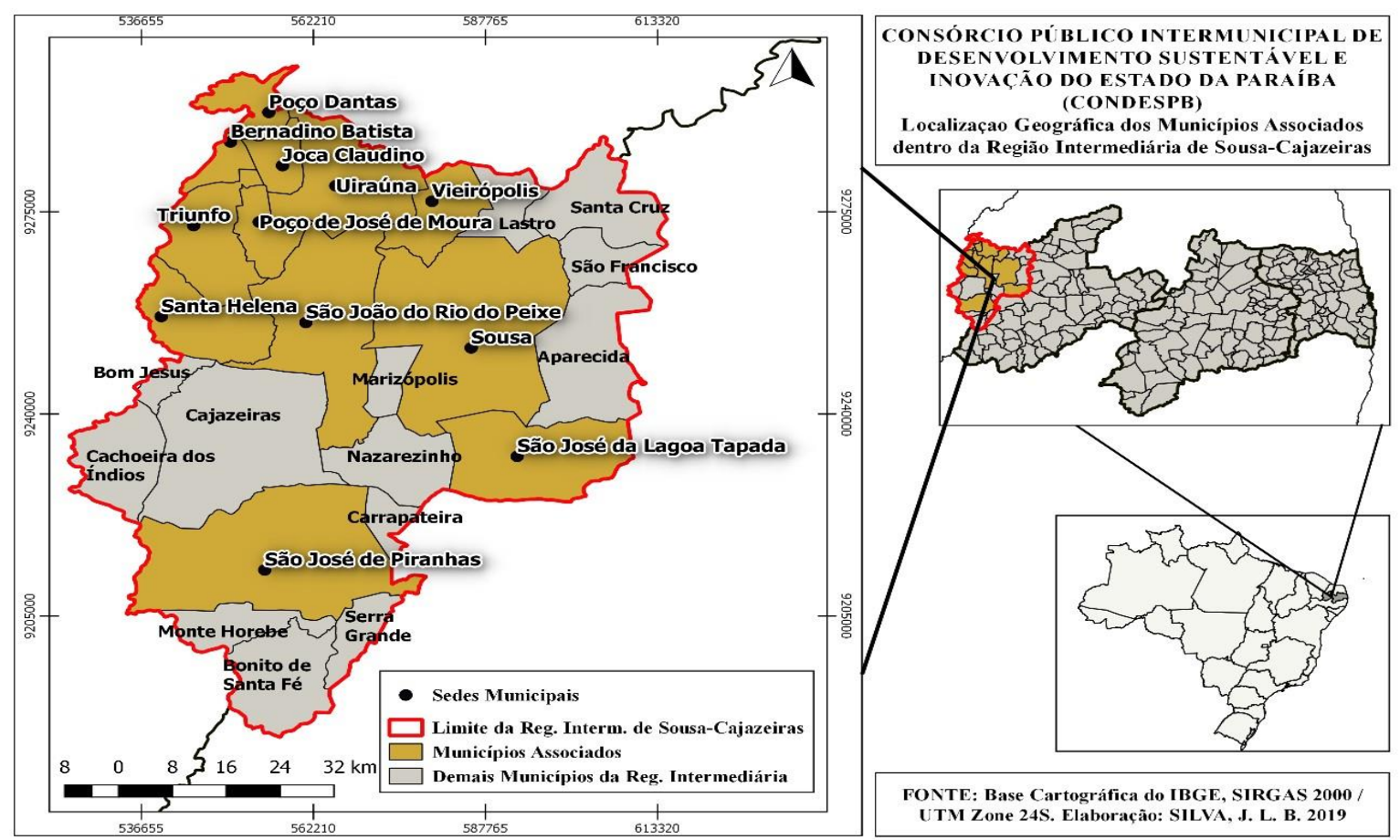

Fonte: Silva (2019) 


\section{Resultados da pesquisa}

\subsection{Panorama do saneamento básico dos municípios do CONDESPB}

A priori é importante destacar que os dados disponíveis sobre a os municípios do sertão paraibano são escassos e possivelmente defasados. O último censo oficial foi realizado pelo IBGE em 2010. Acredita-se que em uma década muitas transformações podem ter ocorrido e que a realidade atual dos integrantes dos CONDESPB pode não ser perfeitamente compatível com o que é retratado neste trabalho. Para tentar minimizar as possíveis divergências, utilizou-se além dos dados do censo 2010 e do Atlas do Desenvolvimento Humano do Brasil - também de 2010 informações disponibilizadas pelo IBGE CIDADES, cujos dados mais recentes são datados de 2017.

A tabela 2 apresenta a população urbana e rural de cada um dos municípios associados ao CONDESPB e as características urbanísticas do entorno dos municípios considerando o levantamento realizado pelo IBGE com moradores em domicílios particulares permanentes em áreas urbanas com ordenamento regular.

Tabela 2 - População dos municípios do CONDESPB: acesso à água, coleta do lixo e banheiro ou sanitário em 2017

CARACTERÍSTICAS URBANÍSTICAS DO ENTORNO DOS MUNICÍPIOS

(Moradores em domicílios particulares permanentes em áreas urbanas com ordenamento regular)

\begin{tabular}{|c|c|c|c|c|c|c|}
\hline \multirow{2}{*}{ MUNICÍPIO } & \multirow{2}{*}{$\begin{array}{c}\text { POPULAÇÃO } \\
\text { TOTAL } \\
\text { (CENSO } \\
\text { 2010) }\end{array}$} & \multicolumn{2}{|c|}{$\begin{array}{l}\text { POPULAÇÃO } \\
\text { (CENSO 2010) }\end{array}$} & \multirow{2}{*}{$\begin{array}{l}\text { DESTINO DO } \\
\text { LIXO } \\
\text { (COLETADO) }\end{array}$} & \multirow{2}{*}{$\begin{array}{c}\text { EXISTÊNCIA } \\
\text { DE } \\
\text { BANHEIRO } \\
\text { OU } \\
\text { SANITÁRIO }\end{array}$} & \multirow{2}{*}{$\begin{array}{c}\text { FORMA DE } \\
\text { ABASTECIMENT } \\
\text { O DE ÁGUA } \\
\text { (REDE GERAL } \\
\text { DE } \\
\text { DISTRIBUIÇÃO) }\end{array}$} \\
\hline & & URBANA & RURAL & & & \\
\hline Bernardino Batista & 3.075 & 858 & 2.217 & 827 & 829 & 831 \\
\hline Joca Claudino & 2.615 & 840 & 1.775 & 835 & 810 & 835 \\
\hline Poço Dantas & 3.751 & 977 & 2.775 & 971 & 939 & 933 \\
\hline $\begin{array}{l}\text { Poço de José de } \\
\text { Moura }\end{array}$ & 3.978 & 1.425 & 2.553 & 450 & 448 & 443 \\
\hline Santa Helena & 5.369 & 2.702 & 2.667 & 896 & 889 & 879 \\
\hline S. J. da Lagoa Tapada & 7.564 & 3.315 & 4.249 & 823 & 921 & 958 \\
\hline S. J. de Piranhas & 19.096 & 10.798 & 8.301 & 10.307 & 10.630 & 10.650 \\
\hline S. J. do Rio do Peixe & 18.201 & 6.885 & 11.316 & 6.712 & 6.803 & 6.737 \\
\hline Sousa & 65.803 & 51.885 & 13.922 & 48.202 & 50.203 & 50.203 \\
\hline Triunfo & 9.220 & 4.312 & 4.911 & 3.983 & 4.177 & 4.187 \\
\hline Uiraúna & 14.584 & 10.349 & 4.235 & 10.029 & 10.128 & 9.941 \\
\hline Vieirópolis & 5.045 & 996 & 4.049 & 994 & 854 & 944 \\
\hline
\end{tabular}

Fonte: IBGE (2017)

Através dessa pesquisa foi possível coletar informações acerca da existência de coleta de lixo, existência de banheiro e o acesso à rede de distribuição de água. Conforme a tabela 2 é 
possível afirmar que dos 12 municípios integrantes do CONDESPB, em 66,6\% deles a população urbana - praticamente em sua totalidade - tem acesso à abastecimento de água e a banheiro/sanitário e à coleta de lixo. Todavia em 33,4\% dos municípios apenas $1 / 3$ da população urbana tem acesso a esses serviços, dentre os quais Poço de José de Moura apresenta a situação mais crítica.

Conforme já mencionado na discussão teórica deste trabalho, com o advento da Lei no 11.445/07, os municípios foram orientados à elaboração de Política e Plano Municipal de Saneamento Básico de acordo com as demandas específicas de sua população, assim como foi possibilitada a constituição de um Conselho e de Fundo Municipal de Saneamento Básico para custear as ações cabíveis. Este trabalho buscou verificar como os municípios responderam a essas recomendações e as informações coletadas foram sintetizadas na tabela 3 abaixo.

Tabela 3 - Existência de política, plano, conselho e fundo municipal de saneamento básico nos municípios integrantes do CONDESPB em 2017

\begin{tabular}{|c|c|c|c|c|}
\hline \multirow[b]{2}{*}{ MUNICÍPIO } & \multicolumn{2}{|c|}{$\begin{array}{c}\text { POLÍTICA E PLANO MUNICIPAL DE } \\
\text { SANEAMENTO BÁSICO }\end{array}$} & \multicolumn{2}{|c|}{$\begin{array}{l}\text { CONSELHO E FUNDO MUNICIPAL DE } \\
\text { SANEAMENTO BÁSICO }\end{array}$} \\
\hline & $\begin{array}{c}\text { Existência de } \\
\text { Política Municipal } \\
\text { de Saneamento } \\
\text { Básico }\end{array}$ & $\begin{array}{l}\text { Existência de Plano } \\
\text { Municipal de } \\
\text { Saneamento Básico }\end{array}$ & $\begin{array}{c}\text { Existência de } \\
\text { Conselho Municipal } \\
\text { de Saneamento }\end{array}$ & $\begin{array}{l}\text { Existência de Fundo } \\
\text { Municipal de } \\
\text { Saneamento Básico }\end{array}$ \\
\hline Bernardino Batista & NÃO & NÃO & SIM & NÃO \\
\hline Poço Dantas & Em elaboração & Em elaboração & NÃO & NÃO \\
\hline $\begin{array}{l}\text { Poço de José de } \\
\text { Moura }\end{array}$ & SIM & NÃO & NÃO & NÃO \\
\hline Santa Helena & NÃO & NÃO & NÃO & NÃO \\
\hline Santarém & NÃO & SIM & NÃO & NÃO \\
\hline $\begin{array}{l}\text { São João do Rio do } \\
\text { Peixe }\end{array}$ & Em elaboração & SIM & NÃO & NÃO \\
\hline $\begin{array}{l}\text { São José da Lagoa } \\
\text { Tapada }\end{array}$ & Em elaboração & SIM & NÃO & NÃO \\
\hline São José de Piranhas & SIM & SIM & NÃO & SIM \\
\hline Sousa & NÃO & NÃO & NÃO & NÃO \\
\hline Triunfo & NÃO & NÃO & NÃO & NÃO \\
\hline Uiraúna & Em elaboração & Em elaboração & Não & Não \\
\hline Vieirópolis & NÃO & NÃO & NÃO & NÃO \\
\hline
\end{tabular}

Fonte: IBGE (2017)

De acordo com a tabela 3, uma década após a promulgação da Lei do Saneamento Básico, apenas 1 dos municípios do CONDESPB havia elaborado a Política Municipal de Saneamento Básico, 4 estavam em fase de elaboração e 58\% ainda não haviam iniciado a construção da política municipal. Com relação ao Plano Municipal de Saneamento Básico 50\% dos associados 
ao consórcio já tinham ou estavam em fase de elaboração e os demais $50 \%$ não haviam iniciado o processo.

A existência de Conselho Municipal de Saneamento foi constatada em apenas 1 dos 12 municípios que formam o CONDESPB: Bernardino Batista. E o Fundo Municipal de Saneamento Básico foi criado apenas no município de São José de Piranhas. Em 41\% dos municípios que integram esta pesquisa não existem nenhum dos elementos que estão sendo verificados na tabela 3. O município de São José de Piranhas apresentou melhor desempenho em relação à adequação à Lei do Saneamento Básico, sendo o único onde existem 3 dos 4 elementos verificados na tabela 3, faltando apenas a constituição do Conselho Municipal de Saneamento para atender integralmente às diretrizes da referida Lei.

Outro aspecto relevante da gestão do saneamento básico nos municípios é a definição de um órgão responsável pela regulação dos serviços em cada segmento. A tabela 4 apresenta o panorama dos municípios membros do CONDESPB quanto à atribuição de responsabilidade a um órgão específico para cuidar dos serviços que compõem o saneamento básico.

Conforme é possível observar na tabela 4, todos os municípios associados definiram um órgão para assumir a responsabilidade pela regulação do serviço de abastecimento de água. Essa informação pode estar associada ao fato mencionado anteriormente que quase $70 \%$ dos municípios pesquisados tem população urbana integralmente assistida no que tange ao acesso à água.

Tabela 4 - Definição de órgão responsável pela regulação de serviços de saneamento

\begin{tabular}{l|c|c|c|c}
\hline \multirow{2}{*}{ MUNICípIO } & \multicolumn{4}{|c}{ REGULAÇÃO DOS SERVIÇOS DE SANEAMENTO } \\
& O município definiu o órgão responsável pela regulação de serviços de saneamento? \\
\cline { 2 - 5 } & $\begin{array}{c}\text { ABASTECIMENTO } \\
\text { DE ÁGUA }\end{array}$ & $\begin{array}{c}\text { ESGOTAMENTO } \\
\text { SANITÁRIO }\end{array}$ & MANEJO DE & MANEJO DE \\
RESÍDUOS \\
SÓLIDOS
\end{tabular}

Fonte: IBGE (2017) 
Em se tratando de esgotamento sanitário mais de $60 \%$ dos municípios estudados já haviam definido um órgão para regulamentação deste serviço. Já em relação ao manejo de águas pluviais e ao manejo de resíduos sólidos nenhum dos municípios chegou a definir um órgão responsável pela regulamentação dos serviços. Vale salientar que a pesquisa do IBGE que possibilitou a coleta dessas informações foi realizada em 2017. Essa informação é extremamente relevante ao inferir que a fragilidade e dificuldade em definir um órgão para trabalhar os resíduos sólidos pode ter sido a motivação para, no ano de 2019, a maioria destes municípios aderirem ao consórcio e alocaram esforços junto aos veteranos para fortalecer a entidade.

Outro aspecto a ser considerado é a existência de licenças ambientais que são prérequisito para elaboração e/ou implementação de projetos que têm relação e/ou podem causar impactos ao meio ambiente. A tabela 5 apresenta a existência de licenças ambientais relativas aos sistemas que compõe o saneamento básico.

Tabela 5 - Municípios do CONDESPB: Existência de licenças ambientais em 2017

\begin{tabular}{|c|c|c|c|c|}
\hline \multirow[b]{2}{*}{ MUNICÍPIO } & \multicolumn{4}{|c|}{$\begin{array}{l}\text { REGULAÇÃO DE LICENÇAS AMBIENTAIS } \\
\text { Existem licenças ambientais relativas aos sistemas de: }\end{array}$} \\
\hline & $\begin{array}{l}\text { ABASTECIMENTO } \\
\text { DE ÁGUA }\end{array}$ & $\begin{array}{l}\text { ESGOTAMENTO } \\
\text { SANITÁRIO }\end{array}$ & $\begin{array}{c}\text { MANEJO DE ÁGUAS } \\
\text { PLUVIAIS }\end{array}$ & $\begin{array}{c}\text { MANEJO DE } \\
\text { RESÍDUOS } \\
\text { SÓLIDOS }\end{array}$ \\
\hline Bernardino Batista & NÃO & NÃO & NÃO & NÃO \\
\hline Poço Dantas & NÃO & SIM & NÃO & SIM \\
\hline Poço de José de Moura & NÃO & SIM & NÃO & NÃO \\
\hline Santa Helena & NÃO & NÃO & NÃO & NÃO \\
\hline Santarém & NÃO & NÃO & NÃO & NÃO \\
\hline São João do Rio do Peixe & NÃO & NÃO & NÃO & NÃO \\
\hline São José da Lagoa Tapada & NÃO & $\operatorname{SIM}$ & NÃO & NÃO \\
\hline São José de Piranhas & NÃO & NÃO & NÃO & NÃO \\
\hline Sousa & SIM & SIM & NÃO & SIM \\
\hline Triunfo & NÃO & NÃO & NÃO & NÃO \\
\hline Uiraúna & NÃO & NÃO & NÃO & SIM \\
\hline Vieirópolis & NÃO & NÃO & NÃO & NÃO \\
\hline
\end{tabular}

Fonte: IBGE (2017)

Conforme é possível observar na tabela 5, 7 dos 12 municípios do CONDESPB não tinha em 2017 nenhuma licença ambiental. Apenas o município de Sousa possui licença para sistemas de abastecimento de água, manejo de águas pluviais e manejo de resíduos sólidos simultaneamente. Poço Dantas também se destaca por possuir licença para sistemas de 
esgotamento sanitário e resíduos sólidos. São José da Lagoa Tapada, Uiraúna e Poço de José de Moura possuem uma das 4 licenças importantes para implementação de sistemas que fazem parte da composição do saneamento básico.

\subsection{Atuação do CONDESPB no saneamento básico dos municípios associados}

Mediante as fragilidades estruturais das pequenas cidades, principalmente do sertão paraibano, a utilização da cooperação federativa através da adesão ao Consórcio representa o desejo dos gestores municipais de amenizarem diversas problemáticas que não teriam capacidade para solucionar individualmente. No caso do CONDESPB isso fica evidente ao folhear o Livro de Ata da instituição no qual estão registradas diversas ações voltadas para resolução de questões relativas ao saneamento básico.

Com base no Livro de Ata do CONDESPB a primeira ação nessa área foi a aprovação do Plano Municipal de Gestão Integrada dos Resíduos Sólidos dos municípios de Bernardino Batista, Joca Claudino, Poço Dantas e Poço de José de Moura, municípios fundadores do Consórcio (ASSEMBLÉIAS..., 2012). Esta ação foi concretizada e existem cópias do Planos Municipais arquivados no escritório do Consórcio. Por conseguinte, em janeiro de 2013 houve a aprovação de um projeto de implantação de uma usina de reciclagem de lixo orçada em mais de cinco milhões de reais. Em maio do mesmo ano, os gestores voltaram a se reunir para dar continuidade à discussão do projeto, tendo como uma das pautas a composição de uma comissão para avaliar a área de terra onde seria instalado um galpão de triagem e implantação de aterro sanitário (ASSEMBLÉIAS..., 2013).

Os registros do Livro de Atas apontam que em setembro de 2014 o CONDESPB havia firmado um Convênio com a Fundação Nacional de Saúde (FUNASA) para construção do aterro sanitário e aquisição de equipamentos e veículos. Dois meses depois os gestores se encontraram para discutir a importância da responsabilidade de acompanhamento das ações para dar celeridade à elaboração do projeto técnico. Na mesma reunião foi tratada a questão das responsabilidades dos municípios quanto ao Meio Ambiente, à Política de Resíduos Sólidos e ao aterro sanitário. Na mesma oportunidade foram discutidas a implementação de ações educativas e a realização de um diagnóstico para levantamento de ações coletivas em prol do desenvolvimento intermunicipal (ASSEMBLÉIAS..., 2014).

Durante a coleta das informações, tomou-se conhecimento de que o convênio com a FUNASA foi cancelado e, por esse motivo, a obra do aterro sanitário não chegou a ser iniciada. 
Todavia, não foram encontrados documentos que apresentassem os fatores que acarretaram o fato. Também não existem registros de execução de ações educativas de forma coletiva na área de saneamento básico através do CONDESPB.

Conforme já mencionado, o Consórcio foi reestruturado e atraiu novos municípios para sua composição. O Livro de Ata aponta que em 2019 a questão do saneamento básico voltou a ser a pauta importante da agenda da instituição, porém o objetivo principal não seria somente como foco na questão dos resíduos sólidos. A atenção dos gestores passou a ser alocada também no abastecimento d'agua e no esgotamento sanitário dos municípios. Outros interesses que ganharam destaque foram a infraestrutura urbano e rural, infraestrutura hídrica e aquisição de máquinas e equipamentos que pudessem facilitar a prestação de serviços públicos através da gestão associada (ASSEMBLÉIAS..., 2019).

Em outubro de 2019 a diretoria do CONDESPB levou à assembleia a proposta de cadastramento de projeto junto ao Ministério do Meio Ambiente - mediante o edital 2019: Gestão de Resíduos Sólidos Urbanos - no valor de 4.800.000,00 destinados à aquisição de doze caminhões compactadores para atender os munícios do consórcio (ASSEMBLÉlAS..., 2019).

Em janeiro de 2021, ainda assolados pela dificuldade de gestão dos resíduos, os gestores decidiram eleger a elaboração de um novo projeto de aterro sanitário como prioridade entre as ações do CONDESPB. A fim de alcançar o árduo objetivo, os prefeitos (as) se comprometeram a conseguir emendas com seus parlamentares para executarem a obra, devido ao caráter de urgência (ASSEMBLÉIAS..., 2021).

No mês seguinte, os gestores se reuniram para discutir as dificuldades relativas à existência de lixões em seus municípios. O objetivo do encontro foi tentar barganhar uma empresa privada para que a mesma pudesse prestar o serviço de coleta e destinação dos resíduos de todos os municípios do CONDESPB que estivessem com lixões ativos. $O$ intuito foi conseguir que a empresa apresentasse uma proposta com valor viável diante da situação financeira dos municípios, mediante a oportunidade de fechar vários contratos articulados pelo Consórcio. Ficou claro na ata que o intuito dos gestores com esta ação é amenizar o problema temporariamente enquanto não conquistam o aterro do Consórcio, e que alguns dos municípios do CONDESPB já têm aterro próprio ou já adotaram alguma estratégia para resolver o problema dos lixões (ASSEMBLÉIAS..., 2021).

Não existem documentos capazes de apresentar os motivos do insucesso das ações e obras pretendidas pelo CONDESPB na área analisada, mas infere-se que as alterações na composição da diretoria, que ocorrem naturalmente devido às mudanças de gestores dos 
municípios, influenciam no rumo que tem sido dado à instituição ao longo dos anos. Mesmo diante de tantas desventuras é preciso reconhecer os esforços dos gestores e a importância da cooperação na tentativa de resolução de problemas comuns, principalmente relativos ao saneamento básico.

\section{Considerações finais}

De acordo com informações disponíveis sobre os aspectos que compõem o saneamento básico dos municípios que integram o Consórcio Público Intermunicipal de Desenvolvimento Sustentável e Inovação do Estado da Paraíba é possível identificar algumas congruências e disparidades. Observa-se que todos os municípios têm bom desempenho em relação ao abastecimento de água e que têm dado mais atenção a esse segmento ao considerar o número de pessoas que tem acesso à água e as ações realizadas pelos municípios na prestação desse serviço.

Outro ponto em comum é a dificuldade de gestão dos resíduos sólidos. A maioria dos municípios pesquisados não têm um órgão próprio que regulamente e acompanhe essa área e não têm licença ambiental. Esse pode ser considerado um fator determinante da adesão ao consórcio e à tentativa de fortalecimento da entidade, pois a construção de um aterro sanitário é uma obra de altíssimo custo, dificilmente viável a um pequeno município. Mas, se fosse implantado e administrado pelo Consórcio poderia atender diversos pequenos municípios simultaneamente e resolver a problemática da destinação dos resíduos.

Com relação ao esgotamento sanitário, considera-se insuficiente o fato de que a maioria da população urbana dos municípios tem acesso a banheiro/sanitário para compreender o desempenho nesse aspecto, já que não foram encontradas outras informações que pudessem complementar a formação de um panorama mais preciso.

Quanto às divergências, foi possível observar que os municípios variam em relação à atenção e aos esforços empregados individualmente nas demais áreas que são abrangidas pelo saneamento básico, por exemplo a escolha de quais ações executar, a decisão sobre elaborar (ou não) políticas, planos, constituir conselhos, dentre outros. Também não foi possível verificar se o debate das questões pertinentes ao saneamento e as ações já implementadas têm relação com o fato de fazer parte ou não de consórcio público. Elucidar esses questionamentos demandaria uma observação mais aproximada de cada realidade e pode ser um passo a diante na continuação deste trabalho. 
Diante dos contrastes nas decisões e ações municipais em uma região com tantas similitudes é perceptível a crescente necessidade de cooperação entre os diferentes entes governamentais e que as vantagens das ações consorciadas precisam ser discutidas e exploradas entre os membros da entidade. Não se trata de uma empreitada simples devido aos escassos recursos, sobretudo para municípios de menor porte, tanto na perspectiva da capacidade técnico-administrativa quanto da operacional. A possibilidade de realizar as demandas de saneamento através de consórcios traz ganhos de escala, redução dos custos da produção e distribuição dos serviços e a ampliação dos investimentos sobre uma base maior de usuários. Fica evidente que essa é a via que os municípios poderão adotar para atender às exigências da Lei no 11 na amplitude que a legislação prevê.

\section{Referências}

ASSEMBLEIAS Gerais Ordinárias e Extraordinárias do Consórcio Intermunicipal de Desenvolvimento Regional do Rio do Peixe. CIDR/NRP. Ata de reunião. Joca Claudino, 2012.

ASSEMBLEIAS Gerais Ordinárias e Extraordinárias do Consórcio Intermunicipal de Desenvolvimento Regional do Rio do Peixe. CIDR/NRP. Ata de reunião. Uiraúna, 2013.

ASSEMBLEIAS Gerais Ordinárias e Extraordinárias do Consórcio Intermunicipal de Desenvolvimento Regional do Rio do Peixe. CIDR/NRP. Ata de reunião. Joca Claudino, 2014.

ASSEMBLEIAS Gerais Ordinárias e Extraordinárias do Consórcio Intermunicipal de Desenvolvimento Regional do Rio do Peixe. CIDR/NRP. Ata de reunião. Uiraúna, 2019.

ASSEMBLEIAS Gerais Ordinárias e Extraordinárias do Consórcio Intermunicipal de Desenvolvimento Regional do Rio do Peixe. CIDR/NRP. Ata de reunião. Uiraúna, 2021.

BASTOS, Rafael Kopschitz Xavier. Oportunidades e desafios para os prestadores municipais de serviços de Saneamento Básico. In: BRASIL. Lei Nacional de Saneamento Básico: perspectivas para as políticas e a gestão dos serviços públicos. Prestação dos serviços públicos de saneamento básico. Brasília, DF: Ministério das Cidades, 2009.

BORJA, Patrícia Campos. Política pública de saneamento básico: uma análise da recente experiência brasileira. Revista Saúde e Sociedade, São Paulo, v. 23, n. 2, p. 432-447, 2014.

BRASIL. Constituição (1988). Constituição da República Federativa do Brasil. Brasília, 1988.

BRASIL. Diretrizes para a definição da Política e Elaboração de Planos Municipais e Regionais de Saneamento Básico. Brasília, DF: Ministério das Cidades/Secretaria Nacional de Saneamento Ambiental, 2010.

BRASIL. Guia para a Elaboração de Planos Municipais de Saneamento. Brasília, DF: Ministério das Cidades/Secretaria Nacional de Saneamento Ambiental, 2011.

BRASIL. Lei Nacional de Saneamento Básico: perspectivas para as políticas e a gestão dos serviços públicos. Prestação dos serviços públicos de saneamento básico. Brasília, DF: Ministério das Cidades/Secretaria Nacional de Saneamento Ambiental, 2009. 
BRASIL. Lei de Saneamento Básico - Lei no 11.445. Brasília, DF: Ministério das Cidades/Secretaria Nacional de Saneamento Ambiental, 2007.

BRITTO, Ana Lucia. A gestão do saneamento no Brasil: desafios e perspectivas seis anos após a promulgação da Lei 11.455/2007. Revista eletrônica de estudos urbanos e regionais, Observatório das metrópoles, Rio de Janeiro, 2012.

CALVO, Maria Cristina Marino; LACERDA, Josimari Telino de; COLUSSI, Claudia Flemming; SCHNEIDER, Ione Jayce Ceola; ROCHA, Thiago Augusto Hernandes. Estratificação de municípios brasileiros para avaliação de desempenho em saúde. Revista Epidemiologia e Serviços de Saúde, Brasília, v. 25, n. 4, out./dez. 2016.

CONFEDERAÇÃO NACIONAL DOS MUNICÍPIOS. Saneamento Básico para Gestores Públicos. Brasília/DF: CNM, 2009.

DIAS, Daniella Maria dos Santos; NEPOMUCENO, Chaira Lacerda. O estatuto da cidade e a democratização da gestão urbana: um estudo de caso na cidade de Marabá - PA. Revista de Direito da Cidade, v. 9, n. 2, 2017.

CORRÊA, Roberto Lobato. O espaço urbano. 4. ed. São Paulo: Ática, 2004.

FARIA, Simone Alves de; FARIA, Ricardo Coelho de. Cenários e perspectivas para o setor de saneamento e sua interface com os recursos hídricos. Revista de Engenharia Sanitária e Ambiental, Rio de Janeiro, v. 9, n. 3, jul./set. 2004.

FERNANDES, Tassiana Justino. Consórcio público intermunicipal como alternativa para a estão de resíduos sólidos em pequenas cidades. In: X EPCC - Encontro Nacional de Produção Científica, 2017, Maringá. Anais [...]. Maringá: UNICESUMAR - Centro Universitário de Maringá, 2017.

FRESCA, Tania Maria. Em Defesa dos Estudos das Cidades Pequenas no Ensino de Geografia. Revista Geografia, Londrina, v. 10, n. 1, p. 27-34, jan./jun. 2001.

INSTITUTO BRASILEIRO DE GEOGRAFIA E ESTATÍSTICA. Sinopse do Censo Demográfico de 2010 - Paraíba. IBGE, 2010. Disponível em:

https://censo2010.ibge.gov.br/sinopse/index.php?dados=29\&uf=25. Acesso em: 5 dez. 2020.

INSTITUTO BRASILEIRO DE GEOGRAFIA E ESTATÍ́STICA. CIDADES Paraíba - MUNIC, Características dos entornos dos municípios. IBGE, 2017. Disponível em:

https://censo2010.ibge.gov.br/sinopse/index.php?dados=29\&uf=25. Acesso em: 5 dez. 2020.

LISBOA, Severina Sarah; HELLER, Léo; SILVEIRA, Rogério Braga. Desafios do planejamento municipal de saneamento básico em municípios de pequeno porte: a percepção dos gestores. Revista de Engenharia Sanitária e Ambiental, Rio de Janeiro, v. 18, n. 4, out./dez. 2013.

MAIA, Doralice Sátyro. Cidades médias e pequenas do Nordeste: Conferência de abertura. In: LOPES, D. M. F.; HENRIQUE, W. (org.). Cidades médias e pequenas: teorias, conceitos e estudos de caso. SEl, Salvador, 2010. 250 p. il. (Séries estudos e pesquisas, 87).

NOVO Marco de Saneamento é sancionado e garante avanços para o País. Governo do Brasil, Brasília, 15 de julho de 2020. Disponível em: https://www.gov.br/pt-br/noticias/transito-etransportes/2020/07/novo-marco-de-saneamento-e-sancionado-e-garante-avancos-para-opais. Acesso em: 13 jan. 2021.

OBSERVATÓRIO MUNICIPALISTA DE CONSÓRCIOS PÚBLICOS. O que é o Observatório Municipalista de Consórcios Públicos? Consórcios Públicos Municipais, 2020. Disponível em: http://www.consorcios.cnm.org.br/. Acesso em: 10 jan. 2021. 
PITERMAN, Ana; REZENDE, Sonaly Cristina; HELLER, Léo. Capital social como conceito-chave para a avaliação do sucesso de consórcios intermunicipais: o caso do CISMAE. Revista de Engenharia Sanitária e Ambiental, Paraná, v. 21, n. 4, p. 825-834, 2016.

ROSSONI, Hygor Aristides Victor; FARIA, Marco Túlio da Silva; SILVA, Amanda Cristina; HELLER, Léo. Aspectos socioeconômicos e de desenvolvimento humano municipal determinantes na ausência de prestadores de serviços de esgotamento sanitário no Brasil. Revista de Engenharia Sanitária e Ambiental, Rio de Janeiro, v. 25, n. 2, mar./abr. 2020.

SENADO aprova novo marco legal do saneamento básico. Senado Notícias, Brasília, 24 de junho de 2020. Disponível em:

https://www12.senado.leg.br/noticias/materias/2020/06/24/senado-aprova-novo-marco-legaldo-saneamento-basico/\#conteudoPrincipal. Acesso em 12 dez. 2020.

SOUSA, Ana Cristina A.; COSTA, Nilson do Rosário. Política de saneamento básico no Brasil: discussão de uma trajetória. Revista História, Ciências, Saúde - Manguinhos, Rio de Janeiro, v. 23, n. 3, jul./set. 2016.

SOUSA, Carlos Di Stefano Silva; SOUSA, Scarlet Cristina Silva; ALVARES, Aline Melo. Diretrizes normativas para o saneamento básico no Brasil. v. 25, n. 43, 2015.

SOUSA, Luana Marriê de Morais; GUEDES, Leonardo Guerra de Rezende. Consórcios Intermunicipais em Municípios de Pequeno Porte: uma alternativa para gestão de resíduos sólidos urbanos. Desenvolvimento Regional em Debate, [S.I.], v. 9, p. 421-433, 2019. 